(C) 2017. This manuscript version is made available under the CC-BY-NC-ND 4.0 license http://creativecommons.org/licenses/by-nc-nd/4.0/

\title{
Novel, smart and RFID assisted critical temperature indicator for supply chain monitoring
}

\author{
Gabriela Simone Lorite ${ }^{\mathrm{a}}$, Tuula Selkäläa ${ }^{\mathrm{a}}$ Teemu Sipola ${ }^{\mathrm{a}}$, Jesús Palenzuela ${ }^{\mathrm{b}}$, Elena Jubete ${ }^{\mathrm{b}}$, Ana \\ Viñuales $^{b}$, Germán Cabañero ${ }^{b}$, Hans J. Grande ${ }^{b}$, Jarkko Tuominen ${ }^{c}$, Sanna Uusitalo ${ }^{c}$, Leena \\ Hakalahti $^{\mathrm{c}}$, Krisztian Kordas ${ }^{\mathrm{a}}$ and Geza Toth ${ }^{\mathrm{a}, *}$ \\ ${ }^{a}$ Microelectronics Research Unit, P.O. Box 4500, FIN-90014 University of Oulu, Finland \\ b Materials Division, IK4-CIDETEC Research Center, Paseo Miramón 196, 20009 Donostia-San Sebastián, Spain \\ ${ }^{\mathrm{c}}$ VTT Technical Research Centre of Finland Ltd., Kaitoväylä 1, FI-90571 Oulu, Finland \\ *Corresponding author; phone: +358 40 8109399, fax: +358 8 5532728, email: geza@ee.oulu.fi
}

\section{Abstract}

In order to reduce food waste and meet the needs of the demanding modern consumer regarding the quality of food items, it is crucial to monitor the supply chain and storage conditions of perishable food products. Considering this scenario, temperature plays an important role on food safety and quality during storage and supply. In this work, a critical temperature indicator (CTI) based on a solvent melting point is developed. Furthermore, the present CTI working principle is improved by the use of microfluidics technology. As final result, a novel and functional CTI-smart sensor which combines irreversible visual color changes and radio frequency identification (RFID) technologies is achieved. Such CTI integrated to a RFID tag provides a unique advantage to monitor the supply chain in real time by the simple use of a RFID reader in strategic points.

Key words: critical temperature indicator, sensor, RFID, microfluidics, supply chain, intelligent packaging

\section{Introduction}

Today's society is increasingly looking for safeguarding quality, health and safety of consumable products. The growing consumer demands have resulted in the rise of ready-to-eat healthy choices as for example fresh cut fruits in take away cups. In this context, it is of great interest from the producer/seller to ensure quality and food safety, since these aspects will have a strong impact on consumer behavior. Any observed spoilage such as variation in appearance, lack of freshness and change in aroma and flavor will turn the product undesirable for consumption. Further than the food appearance, consumers' major concern relies on the foodborne infections caused by microbes and pathogens contamination. In addition to attending to the consumer demands, food quality control will improve the efficiency of food industries, e.g., by reducing the losses due to microbial spoilage of perishable foods.

Food spoilage can be considered as a change in a food product making the product unacceptable for consuming from a sensory point of view (Huis in't Veld, 1996; Gram et al., 2002). Microbial spoilage is the most common cause of food losses reaching $25 \%$ of all foods produced globally (Gram et al., 
2002). Microbial growth usually results in appearance of off-flavours and off-odours as well as textural changes. In particular, temperature accelerates the microbial growth and metabolic activities which can lead to foodborne infections. In fact, foodborne infections and consumer product recalls have driven great interest towards relative humidity and temperature control during cold chain and storage (Paull, 1999). Furthermore, epidemiological investigations clearly show the temperature as the major contributor for foodborne infections (Tirado et al, 2001). Besides the food safety issues, an efficient cold chain would increase the product shelf life and, as consequence, decrease food waste (Parfitt et al., 2010; Kummu et al., 2012). In addition to safety issues, earlier studies have shown that food stored in room temperature suffers from chemical reactions and physical changes which lead to loss in nutritional values (vitamins, amino acids, minerals) and decrease their sensorial characteristics (as discoloration, darkening, loss of flavor/aroma) (Karel, 1984).

Temperature fluctuations are inevitable during the preparation and distribution of perishable food. Small packages such as ready-to-eat fresh cut fruits are more vulnerable to the effects of temperature fluctuations due to the small inherent heat capacity. Several studies show quantitative investigations on the cold chain, indicating the lack of temperature control during supply chain and storage (Likar et al, 1996; Koutsoumanis et al, 2002; Koutsoumanis et al, 2007). Although some factors - for example relative humidity - can be controlled by improving the properties of packaging materials (e.g. migration and barrier), the temperature control strongly relies on the supply chain and storage. Therefore, an effective food safety should be driven by prevention through monitoring and controlling critical parameters in the supply chain.

Novel food packaging technologies are being developed beyond the traditional label information, aiming towards active and intelligent packaging which provides information about the product quality within the supply chain (Ghaani et al. 2016, Heising et al, 2014). Active packaging focuses on the package material and design development in order to maintain or improve the conditions of the packaged food. Antioxidant and antibacterial additives on packaging materials are examples of active packaging. In contrast to active packaging systems, intelligent packaging integrates smart features like sensing, communicating, recording and detecting in order to provide information related to the food's quality to the stakeholders (i.e. manufactures, retailers, consumers) (Restuccia et al., 2010). As consequence, the intelligent packaging will also extend shelf life, improve safety and quality and assist the consumers way of life (easy information and less time spent in shopping) (Yam et al, 2005; Dainelli et al, 2008).

Recent review demonstrated via number of related publications that the research interest in intelligent packaging lags far behind from active packaging (Ghaani et al. 2016). The intelligent packaging development is highly complex and, thus requires cross-disciplinary work on the fields of food science, material science, chemical and electronic engineering. However, the main drawback on the development of intelligent packaging is that its advantages do normally translate into an increase of product price. From this perspective, the smart features should be integrated only in product packages where the income from increased sales/ reduced wastage outnumbers the increased costs of the package. Examples of such products are highly perishable and expensive foods, like fresh cut fruits and frozen fish, whose freshness cannot be easily defined only by mere visual inspection (Heising et al, 2014). The simple information of use-by date in fresh food products completely fails to inform if 
the product has been kept in safe temperature conditions during supply chain and storage before it reaches the users' hands.

In general, there are three main technologies under development for intelligent packaging systems: (i) indicators, (ii) data carriers and (iii) sensors (Kerry et al., 2006). Indicators aim to provide information to the consumer regarding the food quality, e.g. presence/absence or concentration of some substance, temperature etc. Usually the information is displayed by visual changes (O'Grady \& Kerry, 2008). Data carriers devices are used for storage, distribution and traceability purposes and, thus they are extremely relevant to improve the efficiency in the food supply chain (McFarlane \& Sheffi, 2003). In the food packaging industry, barcodes and radiofrequency identification tags (RFID) are the most important current technology (Ham, 2013; Kumar et al, 2009). Finally, sensors can be used in translating a physical or chemical property into a detectable signal which gives information on the occurrence, location and quantification of energy or matter. (Kress-Rogers, 1998).

Temperature indicators based on irreversible change, expressed as a visible response, have demonstrated their potential to monitor and control the distribution and storage conditions of perishable products (Koutsoumanis et al, 2015). In particular, time-temperature indicators (TTI) have been deeply explored in food intelligent packaging as well as reported in many research studies (Kerry et al, 2006; Wanihsuksombat et al, 2010; Maciel et al, 2012; Kuswandi et al, 2014). TTIs are small labels which provide a cumulative indication of the storage temperatures thought visible response. Although some TTIs are already commercially available, the critical temperature selection is quite limited. Moreover, the cumulative response does not provide specific information about the exact point in the supply chain/storage where the critical temperature has been exceeded. In this sense, RFID tags integrated to a simple critical temperature indicator (CTI) could provide more information regarding the distribution chain temperature conditions. RFID is part of the automatic identification technologies allowing the traceability, inventory management, and promotion of quality and safety. In addition, RFID tag can be further designed and implemented by screen printing technology (Martínez-Olmos et al., 2013).

Based on the above issues, we report the design and development of an integrated CTI-RFID in order to monitor the supply chain of fresh cut fruits within critical temperature range of $18-19^{\circ} \mathrm{C}$. The present work describes two different CTI prototypes based on a solvent melting point and visible response. In addition, a novel CTI design based on scalable microfluidics technology is demonstrated. Finally, the microfluidic-CTI is integrated to a custom RFID tag which is readable through a tailor made software, interfaced with a tablet PC allowing easy portability.

\section{Materials and methods}

\subsection{Materials}

Erythrosin B (spirit soluble, 95+\%), hexadecane (ReagentPlus ${ }^{\circledR}, 99 \%$ ) and multi wall carbon nanotubes (O.D. $\times$ L 6-9 $\mathrm{nm} \times 5 \mu \mathrm{m},>95 \%$ ) from Sigma Aldrich and dimethyl sulfoxide (DMSO, $99.5 \%$, anhydrous with molecular sieves) from Scharlau were used.

\subsection{Fabrication of CTI prototypes}


120 CTI prototypes were fabricated in two different designs: horizontal and vertical (these are referring 121 to the direction in which the sensor components are stacked). For the horizontal CTI, cellulose dialysis 122 membrane MWCO $3.5 \mathrm{kD}$ (Spectra/Por ${ }^{\circledR}$ ) and glass sample tube (40 mm long x $7 \mathrm{~mm}$ diameter) were 123 employed. Synthetized Polylactic acid (PLA) film with $0.22 \mathrm{~mm}$ thickness, cellulose filter paper 124 (FILTER-LAB® RM15104252, $60 \mathrm{~g} / \mathrm{m}^{2}$ ), adhesive grey tape consisting of a 27 mesh woven 125 PET/cotton fabric backing coated with a natural rubber adhesive (Tesa ${ }^{\circledR} 4612$ ) and an encapsulating 126 transparent polypropylene adhesive film (Apli) were applied in the fabrication of the vertical CTI. In 127 this case, a mixture of DMSO and erythrosine B were used as ink in order to inkjet printer onto PLA 128 substrates. The printing process was done using an inkjet printer Dimatix DMP 2831.

\subsection{Fabrication of microfluidic-CTI prototype}

130 Acrylic adhesive (Tesa), poly(methyl methacrylate) (Plexiglas), double sided tape (3M), hydrophilic 131 tape (Adhesives Research) and cellulose acetate (Clarifoil) were used to manufacture the parts for the 132 microfluidic label. The parts were cut using cutting plotter (Graphtec Craft Robo Pro). Lamination 133 was performed using table-top laminator (Yosan LM 340) and hot embossing was done using hot134 stamping machine (Madag P2000).

\subsection{Characterization of the developed prototypes}

136 Vertical/horizontal CTI and microfluidic-CTI were assembled and their response was visually monitored in room temperature $\left(+20^{\circ} \mathrm{C}\right)$. In particular, microfluidic-CTI design has an activation layer which could allow the CTI storage in room temperature. More details regarding the activation principle is given in sub-section 3.1. In order to clarify the storage conditions for the microfluidicsCTI, non-activated microfluidic-CTIs were stored under different temperatures for 1-78 days. All tested microfluidic-CTIs were assembled in cold conditions and then immediately transferred to the storage temperatures. The evaluated temperatures were $+22^{\circ} \mathrm{C}$ (room temperature), $+8^{\circ} \mathrm{C}$ (fridge) and $-20^{\circ} \mathrm{C}$ (freezer). For each condition, three microfluidic-CTIs were stored and tested. The microfluidicCTIs were visually monitored and photographed once week. At the end of the storage period, the microfluidic-CTIs were transferred to a pre-cooled $\left(+4^{\circ} \mathrm{C}\right)$ controlled temperature chamber (ESPEC SU-261) and operated by a custom-made LabVIEW program. The microfluidic-CTI was activated and the response visually monitored. The temperature profile was set from $+4^{\circ} \mathrm{C}$ to $+20^{\circ} \mathrm{C}$ with 30 min hold time in each step $(\Delta \mathrm{T})$ as shown in Figure 1. Since the microfluidic-CTI visual change is observed at the critical temperature of $18-19^{\circ} \mathrm{C}, \Delta \mathrm{T}$ was set as $4^{\circ} \mathrm{C}$ in the interval of $4-12^{\circ} \mathrm{C}$ and decreased to $0.5^{\circ} \mathrm{C}$ in the interval $16-20^{\circ} \mathrm{C}$. A photo was automatically taken every $3 \mathrm{~min}$ and/or if the change in the temperature was higher than $1^{\circ} \mathrm{C}$. A non-activated indicator was used each time as a reference. Same setup was used to test microfluidic-CTI after 8 consecutive melting-freezing cycles. In this case, the melting was performed at $+22^{\circ} \mathrm{C}$ while the freezing at $+8^{\circ} \mathrm{C}$. Finally, CTI-smart sensor was characterized using the same controlled temperature chamber while the resistance was measured using Keithley 2636A SourceMeter.

\section{Results and Discussion}


158 The developed CTI is based on the melting point of the non-toxic and transparent solvent DMSO $\left(19^{\circ} \mathrm{C}\right)$ and a color change by adding a dye compound in the system. In previous work, a DMSO melting process was used as a temperature trigger; however, such system involved a more complex structure and chemical reactions (Grande et al. 2010). In the present case, the indicator work principle is illustrated in Figure 2A. In this horizontal design, the DMSO is placed in the end of a glass tube and kept in temperatures lower than $19^{\circ} \mathrm{C}$ while the red pigment Erythrosin B is placed in the other end. In addition, a cellulose dialysis membrane separates the solid state solvent from the dye powder. The dialysis membrane is permeable to the melted solvent. Once the temperature exceeds the DMSO melting point, the transparent solvent flows and reaches the dye compound producing a visible response. At $20^{\circ} \mathrm{C}$, the transparent solvent has melted and started to develop some color change after $20 \mathrm{~min}$ and reached bright red color after 30min (Figure 2B).

In order to fabricate a more industrially viable prototype, maintaining the same principle of components, a vertical design was proposed. In this case, the working principle is based on the solvent flow from top to bottom and vice versa. Figure 3A illustrates the vertical-CTI prototype fabrication. As first step, a mixture of DMSO and erythrosin B was inkjet printed into a packaging polymeric substrate (PLA). A cellulose filter paper interlayer was placed next in order to promote DMSO diffusion. The CTI was optimized by incorporating a perforated plastic layer, which slows down the process, preventing the fast coloration by avoiding the direct contact between the cellulose layer and the solvent reservoir matrix. As top layer, a frozen DMSO-soaked white matrix constructed with cellulose filter paper was placed. This layer acts as a solvent reservoir holding by absorption a saturated amount of solvent. Finally, all layers were encapsulated with adhesive polypropylene transparent film in order to avoid any undesired leaks.

180 The role of the frozen DMSO-soaked layer is to dissolve the dye deposited by inkjet printing. In this case, once the temperature exceeds $19^{\circ} \mathrm{C}$, the DMSO is efficiently transferred vertically through the different intermediate layers from top to bottom and solves ultimately the deposited dye (erythrosin B). As consequence, the mixture DMSO/erythrosin B flows from bottom to top through a diffusion process producing an irreversible red color to the top layer as visible response. In this case, after the CTI is placed at $20^{\circ} \mathrm{C}$, the first visual response started after $30 \mathrm{~min}$ and completely colored after 90 min (Figure 3B).

Although the vertical design presents feasibility for large scale production, the CTI response is not optimum for some applications that require shorter response times $(<90 \mathrm{~min})$. In order to address this problem, a third CTI was designed also based on solvent melting point concept, however, using microfluidics. Such system can be as simple as the flow of a liquid from a reservoir into a channel as well as can be a complex system containing a whole range of functionalities including mixers, reaction chambers, pumps, immobilized biomolecules and sensing surfaces connected to electronics and optics. Based on this, a simple prototype with two chambers (inlet and outlet) connected with a microchannel were designed (Figure 4). In this case, the solvent in a solid state is placed in the inlet chamber. Once the critical temperature is reached, the solvent melts and flows to the outlet chamber via a capillary. For the microfluidic-CTI, DMSO was replaced by hexadecane due to its moderate effect on the used plastic materials. Due to the insolubility of erythrosin B in hexadecane, the dye was replaced by a natural coloring pigment (red paprika powder). 
Figure 5 illustrates the fabrication of the microfluidic label which consists of four main layers. By laminating the Layerl and Layer 2 together, a structure is formed where the two chambers - inlet and outlet - are connected via a capillary. Before adding the lid layer (Layer3) to the structure, a solventfrozen disc (volume $\sim 40 \mu \mathrm{l}$ ) is placed into the inlet chamber. In addition, a piece of filter paper is placed into the outlet chamber in order to retain the solvent, making the process irreversible and enhancing the color of the solvent. The lid (Layer3) and the activation layer (Layer4) are placed using a double-sided tape. The lid (Layer 3 ) seals the chambers and channel; however it contains two small holes in order to allow the capillary action through the channel. Finally, the activation layer (Layer4) blocks the air-holes from the lid (Layer3). The assembled microfluidic-CTI with transparent lid is shown in Figure 6A. As long as the air-holes in Layer3 are closed (non-activated CTI), the solvent does not flow even if the solvent is in liquid state (Figure 6B). Once the activation layer is peeledoff, the CTI is active (i.e. by air contact with the chambers) and the liquid solvent can flow once the melting temperature is exceeded (Figure 6C-D). A white-lid makes only the outlet chamber visible allowing the color change from white to yellow once the critical temperature is reached (Figure 6E). In total 6 samples were tested using the climate chamber; it was observed that the solvent frozen disc starts to melt at $18.5^{\circ} \mathrm{C}$ for all tested samples. The solvent flowed to the outlet chamber immediately at $19^{\circ} \mathrm{C}$ (Video 1). From these observations, the critical temperature of the microfluidic-CTI is determined to be $18.5-19^{\circ} \mathrm{C}$.

In spite of following the similar principles previously explained in the vertical and horizontal designs, the microfluidic-CTI clearly shows additional advantages: (1) it can be stored at higher temperature than the solvent melting point without losing its activity; (2) the label design has a relatively small size ( $35 \mathrm{~mm} \times 10 \mathrm{~mm} \times 2 \mathrm{~mm}$ ), which makes it convenient to use e.g. in food packages; and (3) the critical temperature can be tuned by simply selecting a solvent which has the melting point at the desired temperature area. Furthermore, the microfluidic-CTI presents good feasibility for large scale production and commercialization.

\subsection{Storage conditions for the microfluidic-CTI}

The effect of prolonged storage on the microfluidic-CTI was investigated. The microfluidic-CTI labels were assembled and stored in three different conditions: room temperature $\left(+22^{\circ} \mathrm{C}\right)$, refrigerator $\left(+8^{\circ} \mathrm{C}\right)$ and freezer $\left(-20^{\circ} \mathrm{C}\right)$. For each condition, three samples were tested. All tests were performed without activating the CTI. i.e. Layer4 was not peeled-off, keeping the air holes closed. From the microfluidic-CTI stored at room temperature (RT), it was observed that the hexadecanefrozen disc had completely melted after $10 \mathrm{~min}$ of assembling process. The solvent stayed in the inlet chamber as predicted and no changes were observed after one day (Figure 8A). After one week of RT storage, a slight decrease of solvent in the inlet chamber was observed, which became more evident with time. After one month, no solvent or color trace was observed in the inlet or in the outlet chamber (Figure 8A). This result indicates that at room temperature the solvent evaporates and the usage of natural pigment poses a risk of degradation by light during time. In addition, yellowish color was observed around the microchannel and outlet chamber after 15 days (Figure 8A) indicating partial absorption of the solvent into the layers at RT. All microfluidic-CTI tested in fridge $\left(+8^{\circ} \mathrm{C}\right)$ and freezer $\left(-20^{\circ} \mathrm{C}\right)$ remained exactly the same as after assembly (Figure $8 \mathrm{~B}$ and $\mathrm{C}$, respectively). After the storage period of 73-78 days, the microfluidic-CTIs were activated (Layer 4 peeled off) and placed into the controlled temperature chamber. In both cases, i.e. microfluidic-CTI stored $\left(+8^{\circ} \mathrm{C}\right)$ and 
freezer $\left(-20^{\circ} \mathrm{C}\right)$, showed the same behavior as observed for the microfluidic-CTI tested immediately after being assembled (Video 1). This result clearly demonstrates that the microfluidic-CTI functionality is not affected by prolonged storage under $+8^{\circ} \mathrm{C}$.

In addition to the storage tests, the microfluidic-CTI durability was tested by consecutive freezingmelting cycles. After the label assembling, the non-activated microfluidic-CTI was placed at RT. As expected, the solvent melted but the liquid did not flow to the outlet chamber (Figure 8A). After 8 freezing-melting cycles, no leaks, damages or stains in the filter paper were observed (Figure 8B). Moreover, after activation the microfluidic-CTI kept its functionality suggesting that the developed CTI can tolerate temperature changes.

\subsection{CTI-smart sensor for real-time monitoring}

The proposed CTI-smart sensor integrates the microfluidic-CTI to a RFID tag in order to remotely detect the melting of the solvent once the critical temperature is reached. The working principle is based on a closed circuit, which the resistance changes upon a contact with the hexadecane-paprika mixture. The CTI-smart sensor was fabricated with some modifications in the original microfluidicCTI design as shown in Figure 9. Copper contacts ( 500 $\mathrm{nm}$ thickness) are sputtered to the Layer1 as an open circuit and as a following step Layer 1 was laminated with Layer2 (Figure 9B). The circuit was closed by placing multi-walled carbon nanotubes (MWCNTs)/ethanol dispersion between the copper contacts. After ethanol evaporation, the resistance was measured. MWCNTs concentration on the copper contacts was adjusted to achieve the resistance of $\sim 1 \mathrm{k} \Omega$ (Figure $9 \mathrm{C}$ ). Once such resistance was reached, the hexadecane-paprika frozen disc was placed in the inlet chamber as well the filter paper on top of the circuit in the outlet chamber (Figure 9D). Finally, the lid (Layer3) and activation layer (Layer 4) were added with double-sided tape (Figure 9E). Once the CTI-smart sensor was activated (Layer4 peeled off) and the critical temperature was reached, the solvent melted and flowed to the outlet chamber disturbing the MWCNT connection (Figure 9F).

The CTI-smart sensor was placed in the controlled temperature chamber and the resistance and temperature profiles were recorded (Figure 10A- red curve). It is clear that the resistance rapidly increases (from $\sim 1 \mathrm{k} \Omega$ to $8 \mathrm{k} \Omega$ ) after the critical temperature is reached (Figure $10 \mathrm{~A}$ - black curve). The sharp and immediate resistance response at the critical temperature is the key feature to establish a threshold level and to connect the sensor to a passive RFID tag. Furthermore, the resistance of a non-activated sensor was measured at room temperature for 26 hours in order to investigate possible resistance variations in the copper-MWCNTs contact in such conditions. No significant resistance change was observed (overall change $\sim 30 \Omega$ ) as showed in Figure $10 \mathrm{~B}$.

A self-made passive RFID/NFC sensor tag was built by using a Melexis MLX90129 sensor tag IC (ISO 15693, 13.56 MHz) (Figure 11A). A rectangular antenna coil (32mm width, 51mm height) was designed and etched on a $200 \mu \mathrm{m}$ FR-4 sheet. Finally, the sensor tag IC and its peripheral components were placed inside the coil structure. The RFID sensor tag was designed for battery-less operation, taking its power from RFID reader/writer RF-field. The passive RFID/NFC sensor tag was connected to the CTI-smart sensor using copper wires (Figure 11B-C). The wires were soldered to the tag and fixed with silver paste and epoxy on the copper-plastic end. Considering the resistance change from 
$1 \mathrm{k} \Omega$ to $8 \mathrm{k} \Omega$ at the critical temperature, the threshold level was set to $2 \mathrm{k} \Omega$ i.e. above this value the RFID tag should show that the temperature had exceed $19^{\circ} \mathrm{C}$.

In order to read the RFID tag, a custom software reading sensor was written using National Instruments LabVIEW. A commercial metraTec DeskID ISO RFID reader/writer (ISO 15693, 13.56 $\mathrm{MHz}$ ) was used and interfaced with a tablet PC for portability reasons. In brief, the custom software was designed to compare the CTI-smart sensor resistance value against a $2 \mathrm{k} \Omega$ reference resistor (Figure 11D):

- If the value is lower than $2 \mathrm{k} \Omega \Rightarrow$ the CTI-smart sensor is non-activated (Layer4 in place) or have not been in critical temperature and the application visually shows an intact chain (cold chain intact).

- If the value is higher than $2 \mathrm{k} \Omega \Rightarrow$ the CTI-smart sensor had reached the critical temperature and the application visually shows a broken chain (cold chain broken).

The ability to remotely read the signal coming from the CTI-smart sensor connected to the RFID sensor tag was tested (Video 2). The CTI-smart sensor was taken from the fridge $\left(+8^{\circ} \mathrm{C}\right)$ and placed at room temperature $\left(22^{\circ} \mathrm{C}\right)$. The application showed the intact chain sign until approximately 4 minutes after the CTI-smart sensor activation (Layer4 peeled off) (Figure 12A). At $\sim 6$ minutes after activation, the yellowish color in the outlet chamber started to be visible producing the visual response (Figure 12B). The application status changed to "cold chain broken" after 15 seconds from the visual response (Figure 12C). In addition, the CTI-smart sensor integrated with the RFID tag was placed in a fridge $\left(+8{ }^{\circ} \mathrm{C}\right)$ and the tag was read after $30 \mathrm{~min}, 1$ day, 2 days and 3 days in order to test the RFID tag under lower temperature. The results did not show any restriction regarding to the RFID tag stored in fridge for the studied period.

\section{Conclusions}

A CTI-smart sensor prototype development and its performance were demonstrated. Although the presented microfluidic-CTI is developed for a critical temperature (CT) around $18-19^{\circ} \mathrm{C}$, the sensor can be modified to attend other critical temperatures by simply replacing the solvent by other CTmatch solvent. For example, the solvent could be replaced by colored water in order to detect temperatures higher than $0^{\circ} \mathrm{C}$ for cold supply chains in which the product must be frozen. The compatibility between the microfluidic materials and the chosen solvent for other applications need to be tested. Moreover, by using microfluidic technology a matrix array can be designed for discriminating different ranges of temperatures. The indicator visible response was successfully converted to a remotely readable signal by connecting the microfluidic-CTI to a RFID tag. Our results clearly showed that a fast response (about $6 \mathrm{~min}$ ) after the sensor is exposed to the critical temperature. Therefore, this CTI-smart sensor could be successfully applied to monitor and trace the supply chain simply by a RFID reading. In addition, the storage stability tests demonstrated that they can be stored at fridge and freezer temperatures for several months without losing the functionality. From the industrial point of view, roll-to-roll (R2R) printing facilities can be used to produce R2R hot embossed microfluidic chips allowing the use of this technology to an industrially applicable level. Further development of the RFID tags using printing technologies could also allow the consumer to 
monitor the food temperature route through a mobile app. Printed RFID tags do not require passing through chemical baths and, thus biodegradable and food compatible materials can be used.

\section{Acknowledgements}

Funding received from EU under the Seventh Framework Program (FP7) in project Susfoflex (Smart and sustainable food packaging utilizing flexible printed intelligence and materials technologies) is acknowledged.

\section{References}

Dainelli, D., Gontard, N., Spyropoulos, D., Zondervan-van den Beuken, E., \& Tobback, P. (2008). Active and intelligent food packaging: legal aspects and safety concerns. Trends in Food Science \& Technology, 19, S103-S112.

Ghaani, M.,Cozzolino, C.A., Castelli G., \& Farris S. (2016) An overview of the intelligent packaging technologies in the food sector, Trends in Food Science \& Technology 51, 1-11.

Gram, L., Ravn, L., Rasch, M., Bruhn, J.B., Christensen, A.B., \& Givskov, M. (2002) Food spoilage - interactions between food spoilage bacteria, International Journal of Food Microbiology $78,79-97$.

Grande, T. H-J., Pomposo, A.J.A., Martinez, C. P-G., \& Viñuales, A. (2010) Temperature-time indicator system based on irreversible colour changes, and corresponding method. patent WO 2010109023 A1.

Han, J. H. (2013). A review of food packaging technologies and innovations. Innovations in food packaging (p. 3). Amsterdam: Ed. Elsevier Academic Press.

Heising, J. K., Dekker, M., Bartels, P. V., \& Van Boekel, M. A. J. S. (2014). Monitoring the quality of perishable foods: opportunities for intelligent packaging. Critical reviews in food science and nutrition, 54(5), 645-654.

Huis in’t Veld, J.H.J., (1996) Microbial and biochemical spoilage of foods: an overview, International Journal of food Microbiology 33, 1-18.

Karel, M. (1984) Chemical effects in food stored at room temperature. Journal of Chemical Education, 61(4), 335-339.

Kerry, J. P., O'grady, M. N., \& Hogan, S. A. (2006). Past, current and potential utilisation of active and intelligent packaging systems for meat and muscle-based products: A review. Meat science, 74(1), 113-130.

Kerry, J. P., O'Grady, M. N., \& Hogan, S. A. (2006). Past, current and potential utilisation of active and intelligent packaging systems for meat and muscle-based products: a review. Meat Science, 74, 113-130.

Koutsoumanis, K. \& Gougouli, M. (2015) Use of Time Temperature Integrators in food safety management Trends in Food Science \& Technology 43, 236-244. 
Koutsoumanis, K. \& Angelidis, A.S. (2007) Probabilistic Modeling Approach for Evaluating the Compliance of Ready-To-Eat Foods with New European Union Safety Criteria for Listeria monocytogenes Applied and Environmental Microbiology 73, 4996-5004.

Koutsoumanis, K., Giannakourou, M.C., Taoukis, P.S. \& Nychas, G.J.E. (2002) Application of shelf life decision system (SLDS) to marine cultured fish quality International Journal of Food Microbiology 73, 375- 382.

Kress-Rogers, E. (1998). Terms in instrumentation and sensors technology. Instrumentation and sensors for the food industry (pp. 673-691). Cambridge, UK: Wood head Publishing Ltd.

Kumar, P., Reinitz, H. W., Simunovic, J., Sandeep, K. P., \& Franzon, P. D. (2009).Overview of RFID technology and its applications in the food industry. Journal of Food Science, 74, R101-R106.

Kummu, M.,de Moe, H., Porkka, M., Siebert, S, Varis O. \& Ward P.J. (2012) Lost food, wasted resources: Global food supply chain losses and their impacts on freshwater, cropland, and fertiliser use Science of the Total Environment 438, 477-489.

Kuswandi, B., Oktaviana, R., Abdullah, A. \& Heng, L.Y. (2014). A Novel On-Package Sticker Sensor Based on Methyl Red for Real-Time Monitoring of Broiler Chicken Cur Freshness. Packaging Technology and Science, 27, 69-81

Likar, K. \& Jevsnik, M. (1996) Cold chain maintaining in food trade Food Control 17, 108-113.

Maciel, V.B.V., Yoshida, C.M.P. \& Franco, T.T. (2012). Development of a prototype of a coloumetric temperature indicator for monitoring food quality. Journal of Food Engineering, 111, 21-27.

Martínez-Olmos, A., Fernández-Salmerón, J., Lopez-Ruiz, N., Rivadeneyra Torres, A., CapitanVallvey, L.F. \& Palma, A.J. (2013) Screen Printed Flexible Radiofrequency Identification Tag for Oxygen Monitoring. Analytical Chemistry 85 (22), 11098-11105

McFarlane, D., \& Sheffi, Y. (2003). The impact of automatic identification on supply chain operations. International Journal of Logistics Management, 14, 1-17.

O'Grady, M. N., \& Kerry, J. P. (2008). Smart packaging technology. In F. Toldra (Ed.), Meat biotechnology (pp. 425-451). New York: Ed. Springer.

Parfitt, J., Barthel, M., \& Macnaughton S. (2010) Food waste within food supply chains: quantification and potential for change to 2050, Phil. Trans. R. Soc. B 365, 3065-3081.

Paull, R.E. Effect of temperature and relative humidity on fresh commodity quality (1999)

Restuccia, D., Spizzirri, U. G., Parisi, O. I., Cirillo, G., Curcio, M., Iemma, F., et al. (2010). New EU regulation aspects and global market of active and intelligent packaging for food industry applications. Food Control, 21, 1425-1435.

Tirado, C. \& Schmidt (2001) WHO Surveillance Programme for Control of Foodborne Infections and Intoxications: Preliminary Results and Trends Across Greater Europe Journal of Infection 43, 80-84.

Wanihsuksombat, C., Hongtrakul, V. \& Suppakul, P. (2010) Development and characterization of a prototype of lactic acid-based time-temperature indicator for monitoring food product quality. Journal of Food Engineering, 100, 427-434. 
395 Yam, K. L., Takhistov, P. T., \& Miltz, J. (2005). Intelligent packaging: concepts and applications. 396 Journal of Food Science, 70(1), R1-R10. 


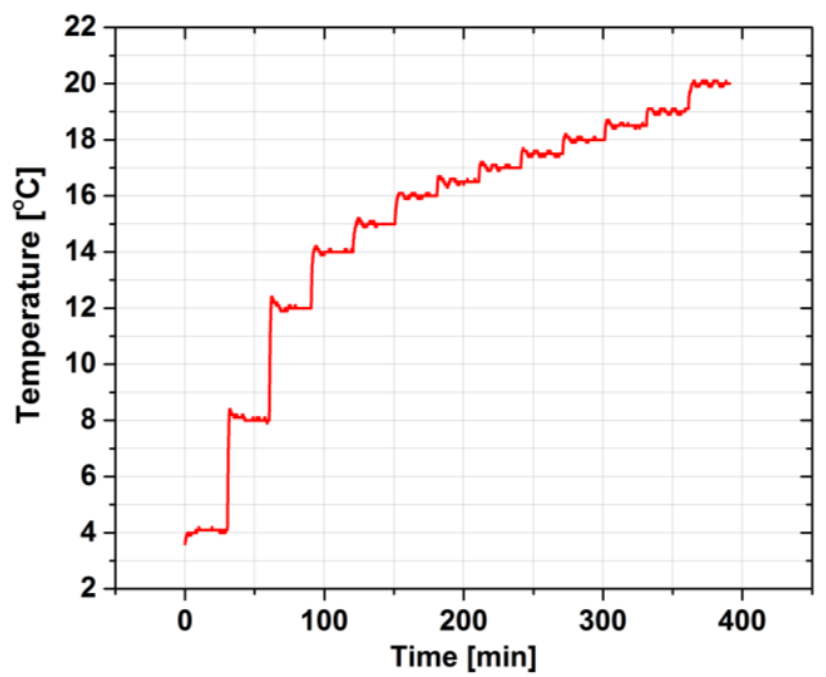

399 Figure 1. Temperature profile used during microfluidics-CTI testing in the controlled temperature chamber.

A

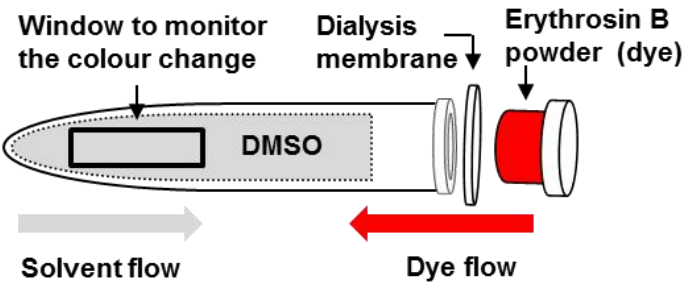

B

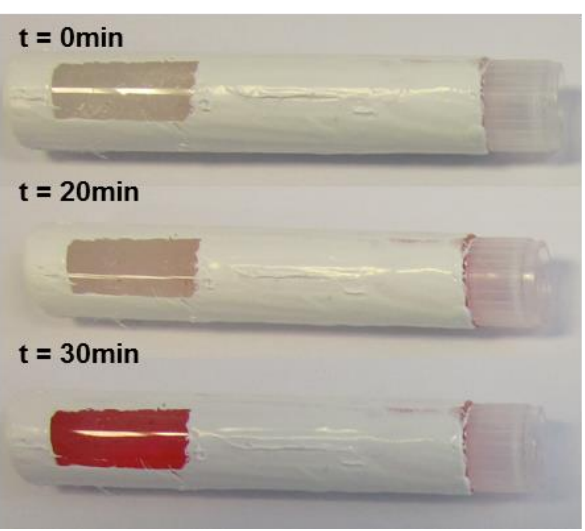

Dye flow

401 Figure 2. (A) Scheme of horizontal CTI design based on melting point of DMSO. (B) Horizontal -CTI pictures after 0, 40220 and 30 minutes at $20^{\circ} \mathrm{C}$. The horizontal-CTI design presented cylindrical shape with $0.8 \mathrm{~cm}$ of diameter and $4 \mathrm{~cm}$ of 403 length. 
A

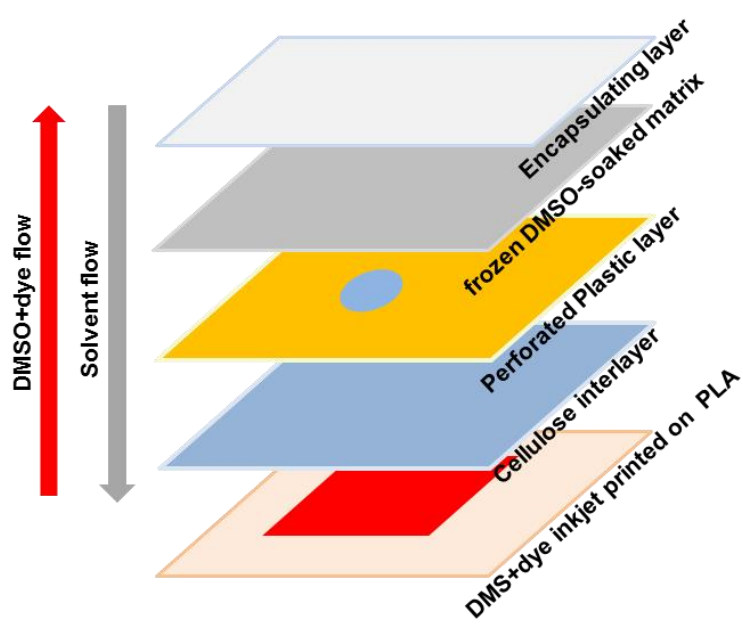

B
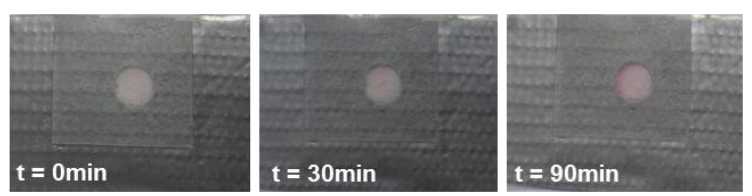

Figure 3. (A) Scheme of vertical design CTI based on melting point of DMSO. (B) Top view of vertical design CTI pictures after 0,30 and 90 minutes at $20^{\circ} \mathrm{C}$.

\section{Microchannel}

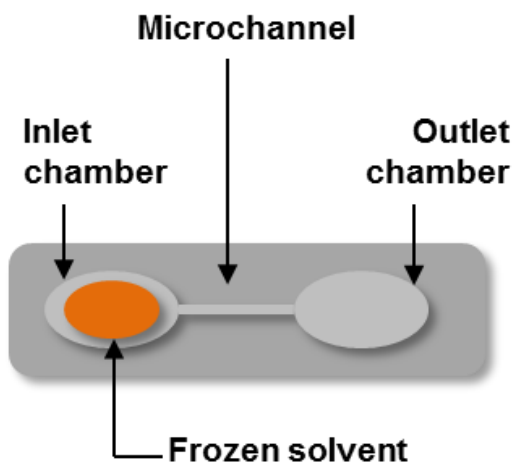

Figure 4. Scheme for microfluidic-CTI design.

410 Figure 5. Scheme of microfluidics-CTI 4 layer structure. Layer1: $250 \mu \mathrm{m}$ thick cellulose acetate foil with a hot embossed microfluidic channel; Layer2: PMMA, double-sided tape and hydrophilic tape with cut-through holes forming chamber structures; Layer3: lid layer formed from double-sided tape and PMMA with cut air holes on top for both chambers; 413

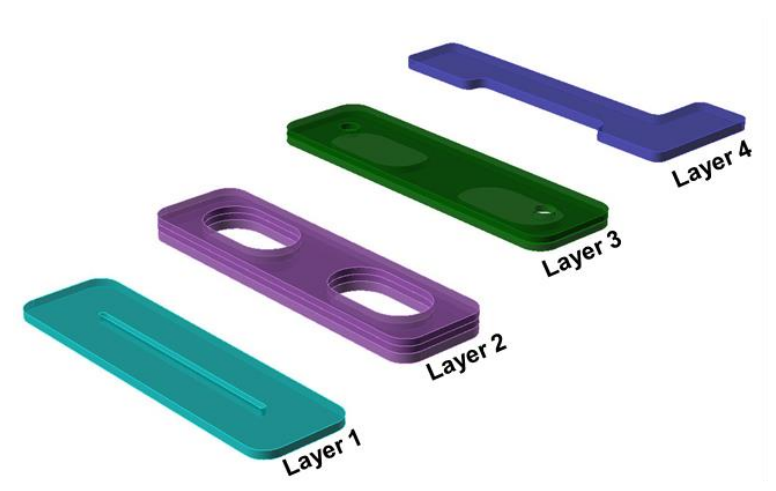
Layer4: activation tape layer. 

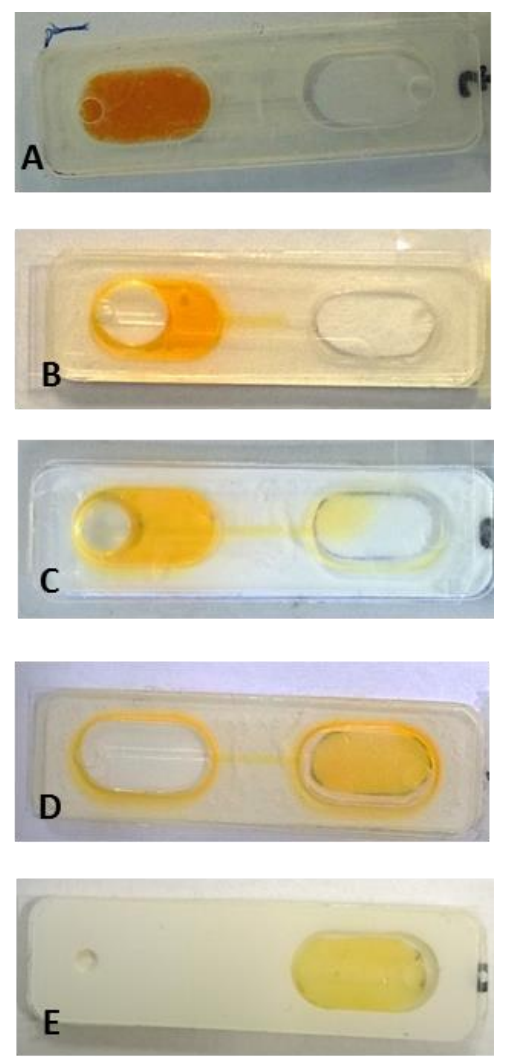

415 Figure 6. Pictures of microfluidic-CTI with visual response: (A) Non-activated microfluidic-CTI under $19^{\circ} \mathrm{C}$, solvent remains frozen; (B) Non-activated microfluidic-CTI above $19^{\circ} \mathrm{C}$, solvent is melted but remains in the inlet channel; (C) Activated microfluidic-CTI above $19^{\circ} \mathrm{C}$, solvent in liquid state flow to the outlet chamber; (D) Solvent in liquid state is completely absorbed by the filter paper in the outlet chamber; (E) Alternative lid option for easy visualization by the final consumer, just the outlet chamber is visible.

A

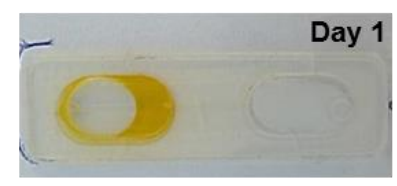

B

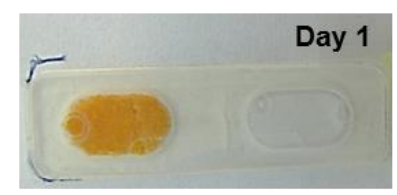

C

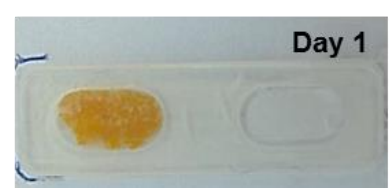

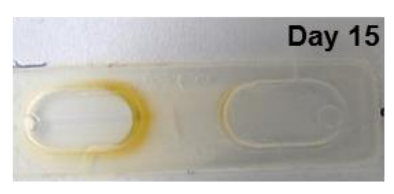
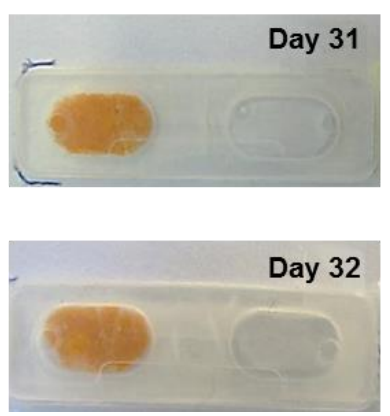

Day 32
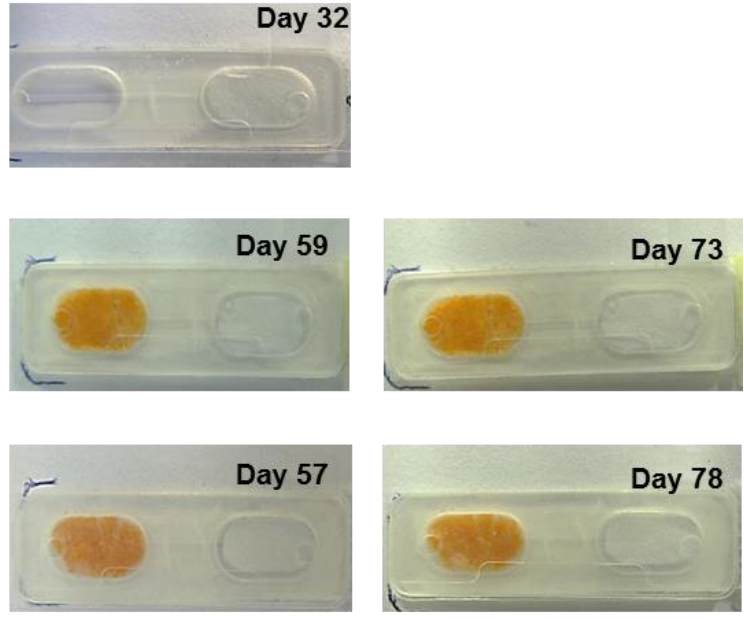

421 Figure 7. Pictures of a microfluidic-CTI after storage period at (A) $+22^{\circ} \mathrm{C},(\mathrm{B})+8^{\circ} \mathrm{C}$ and $(\mathrm{C})-20^{\circ} \mathrm{C}$. Storage period is marked on each picture. 

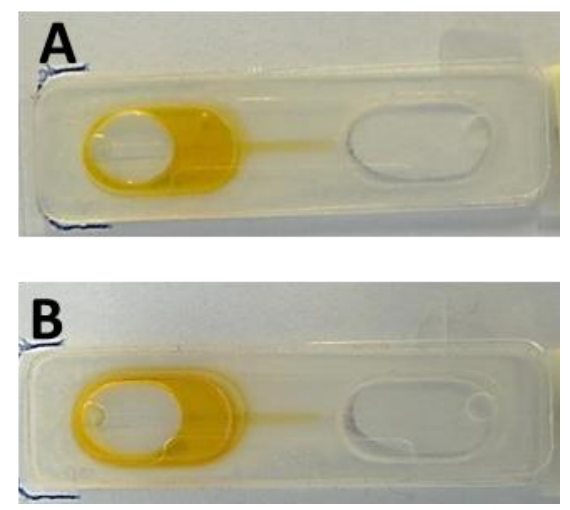

424 Figure 8. Pictures of microfluidic-CTI taken after (A) $1^{\text {st }}$ freezing-melting cycle and (B) $7^{\text {th }}$ freezing-melting cycle.
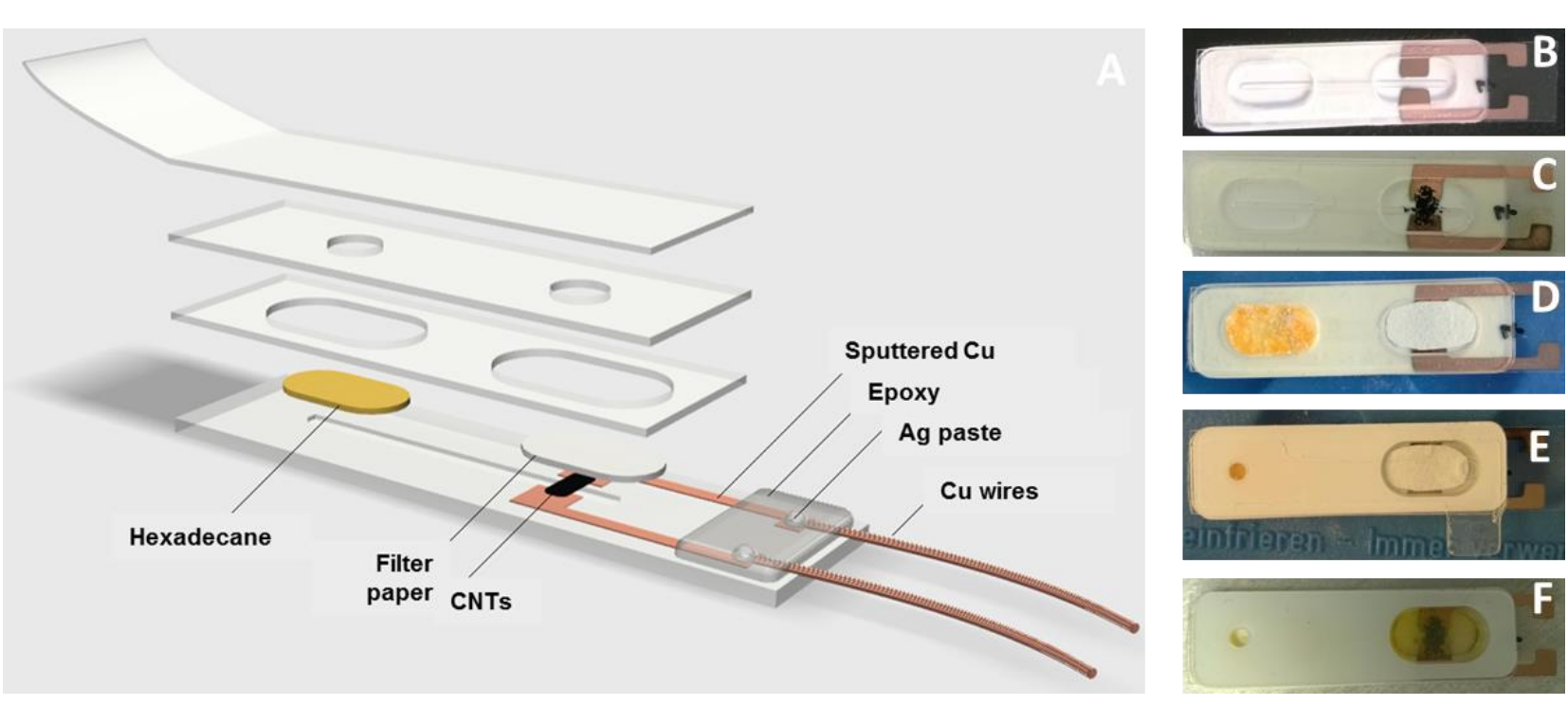

Figure 9. (A) Scheme of microfluidic-CTI modifications for the development of CTI-smart sensor. (B) Copper contacts were sputtered as an open circuit in Layerl using masked cellulose acetate film and physical vapor deposition (PVD) method. (C) MWCNTs/ethanol dispersion was deposited in order to close the circuit. (D) Hexadecane-paprika frozen disc placed in the inlet chamber and filter paper in the outlet chamber. (E) CTI-smart sensor final assembly (with activation layer). (F) Activated CTI-smart sensor, at room temperature
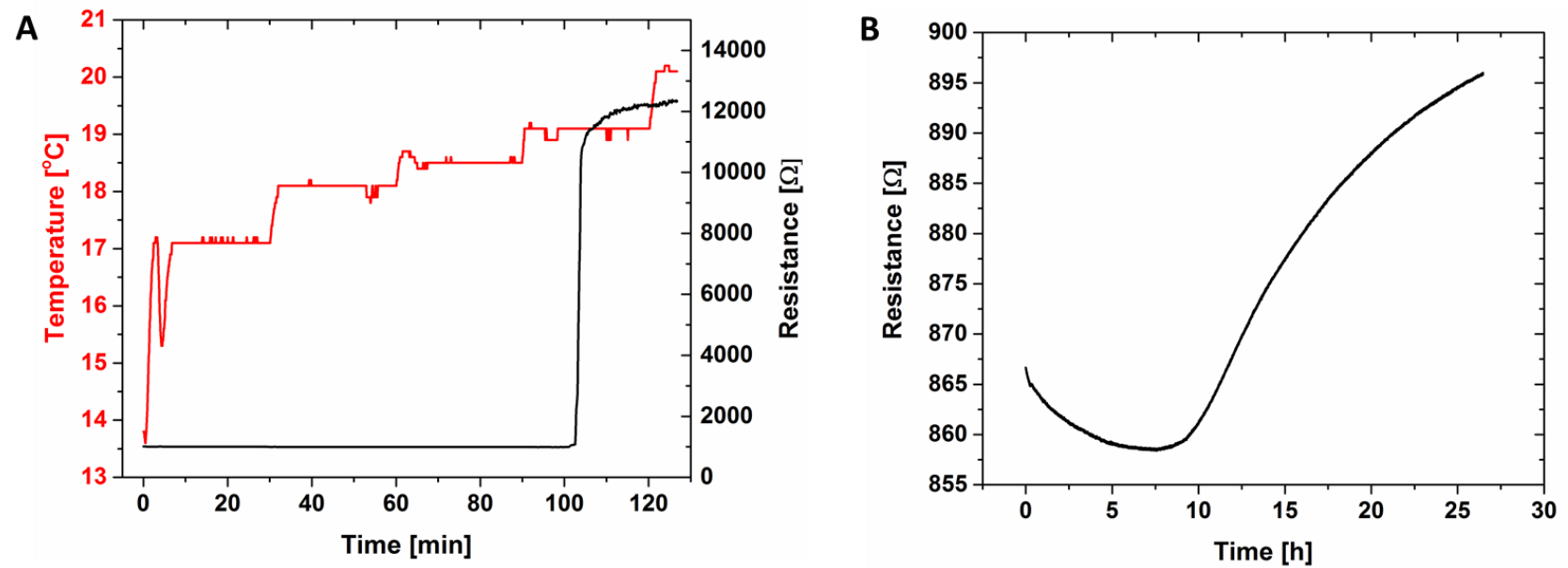

Figure 10. (A) Resistance versus temperature behavior of an activated CTI-smart sensor recorded in controlled temperature chamber and (B) Non-activated CTI-smart sensor resistance behavior in room temperature for 26 hours. 
A

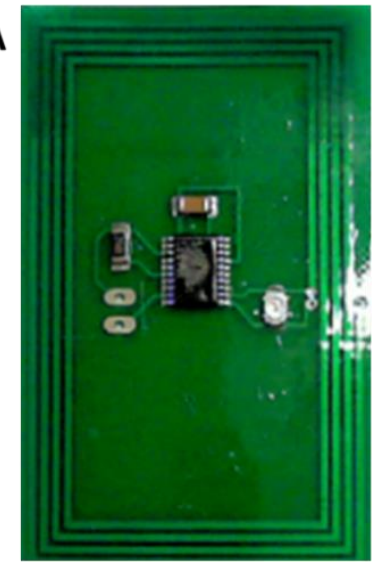

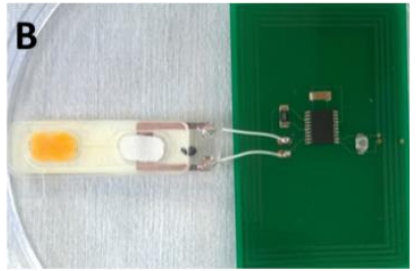

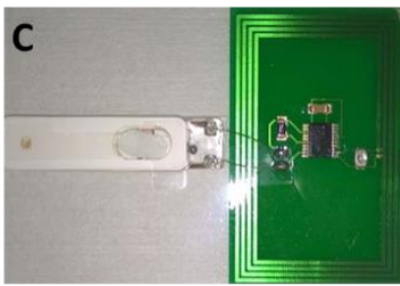

D

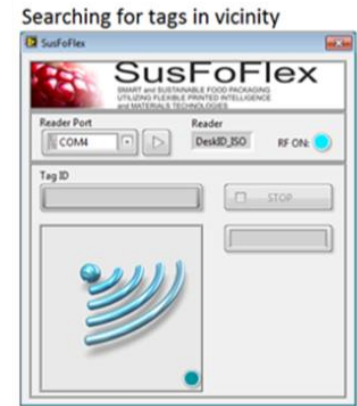

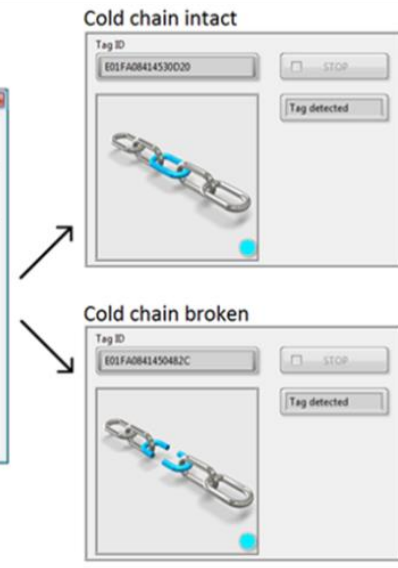

Figure 11. (A) Custom made passive RFID/NFC sensor tag. (B) CTI-smart sensor connected to RFID tag. (C) Final assembly for CTI-smart sensor. (D) Custom software reading: cold chain intact $=$ non-activated or have not been in critical temperature and cold chain broken $=$ CTI-smart sensor had reached the critical temperature.
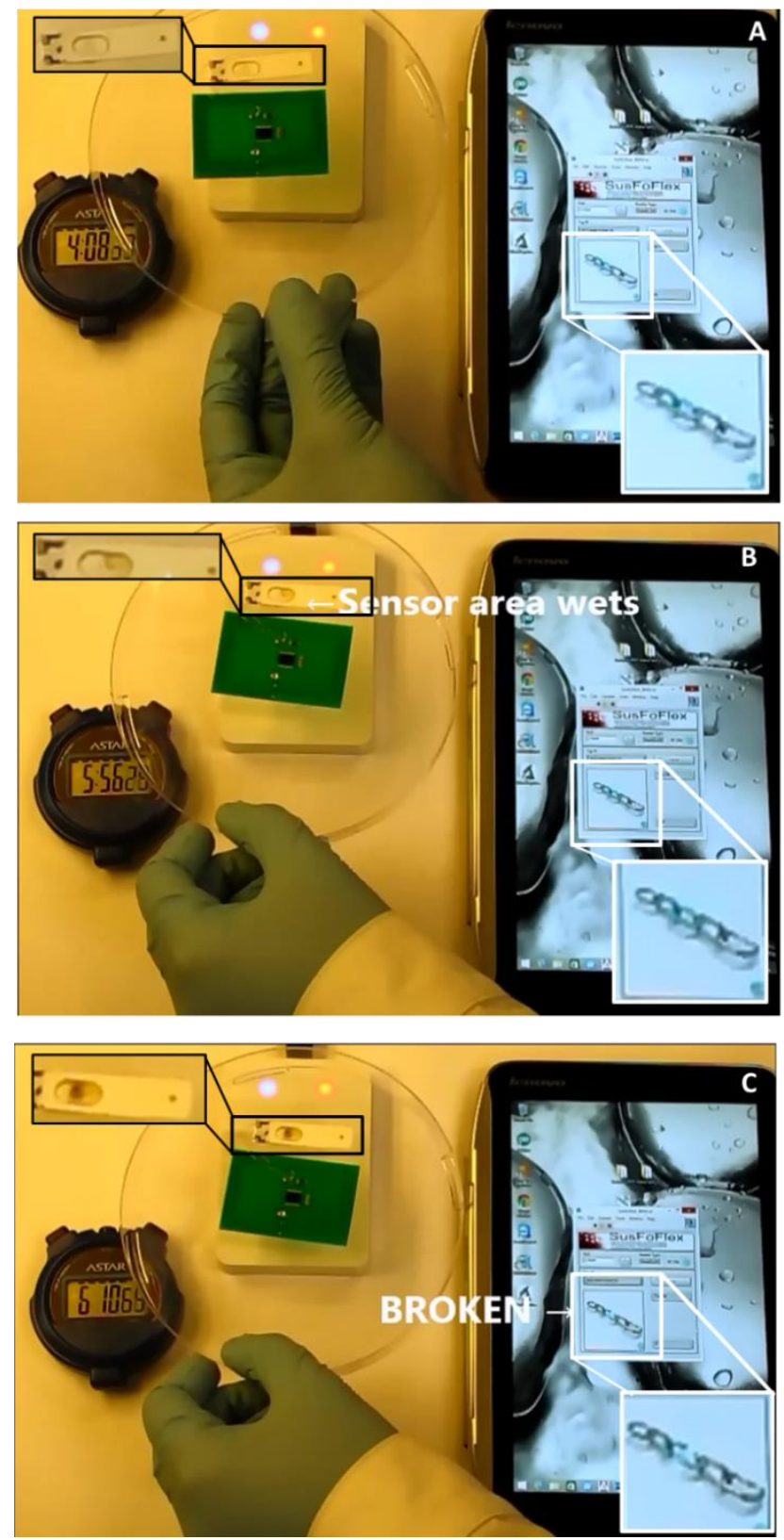
439 Figure 12. Remote reading of the activated CTI-smart sensor in room temperature (A) after 4:08 minutes (no visual change 440 and cold chain intact), (B) after 5:56 minutes (slight visual change and cold chain intact) and (C) after 6:10 minutes (clear 441 visual change and cold chain broken). 